\section{A Bridge to Active Learning: A Summer Bridge Program Helps Students Maximize Their Active-Learning Experiences and the Active-Learning Experiences of Others}

Katelyn M. Cooper, Michael Ashley, and Sara E. Brownell*

School of Life Sciences, Arizona State University, Tempe, AZ 85287

\begin{abstract}
National calls to improve student academic success in college have sparked the development of bridge programs designed to help students transition from high school to college. We designed a 2-week Summer Bridge program that taught introductory biology content in an active-learning way. Through a set of exploratory interviews, we unexpectedly identified that Bridge students had developed sophisticated views of active learning, even though this was not an explicit goal of the program. We conducted an additional set of semistructured interviews that focused on active learning and compared the interviews of Bridge students with those from non-Bridge students who had been eligible for but did not participate in the program. We used the constant comparative method to identify themes from the interviews. We found that Bridge students perceived that, because they knew how to approach active learning and viewed it as important, they benefited more from active learning in introductory biology than non-Bridge students. Specifically, Bridge students seemed to be more aware of their own learning gains from participating in active learning. Compared with the majority of non-Bridge students, the majority of Bridge students described using a greater variety of strategies to maximize their experiences in active learning. Finally, in contrast to non-Bridge students, Bridge students indicated that they take an equitable approach to group work. These findings suggest that we may be able to prime students to maximize their own and other's experiences in active learning.
\end{abstract}

\section{INTRODUCTION}

Summer bridge programs are designed to "bridge" the transition from high school to college. These are often intensive multiweek experiences that occur before the start of a student's first year in college and are generally intended to help students adapt to the college academic environment. Summer bridge programs usually target students who are at risk for prematurely departing from science, technology, engineering, and mathematics (STEM) majors, including historically underrepresented racial minority (URM), first-generation, and low-income students (e.g., Buck, 1985; Stolle-McAllister, 2011; Strayhorn, 2011; Tomasko et al., 2013).

Students often face higher academic expectations in college compared with high school, as well as larger class sizes, fewer opportunities to interact with instructors, and the need to establish new social relationships (Terenzini et al., 1994). While the overarching purpose of many bridge programs is to improve student persistence in college (Garcia, 1991; Strayhorn, 2011), additional program goals often range from building community and creating social support systems (e.g., Stolle-McAllister, 2011; Strayhorn, 2011; Tomasko et al., 2013) to improving student academic success (e.g., Buck, 1985; Ackermann, 1991; Garcia, 1991; Wischusen and Wischusen, 2007; Wischusen et al., 2010; Walpole et al., 2008; Cabrera et al., 2013). These efforts collectively aim to equip students with a tool kit to successfully respond to the differences between high school and college experiences (Buck, 1985; Murphy et al., 2010; Strayhorn, 2011).
Jeff Schinske, Monitoring Editor Submitted May 2, 2016; Revised September 15, 2016; Accepted September 22, 2016

CBE Life Sci Educ March 1, 2017 16:ar17 DOI:10.1187/cbe.16-05-0161

*Address correspondence to: Sara E. Brownell (sara.brownell@asu.edu).

(c) 2017 K. M. Cooper et al. CBE-Life Sciences Education ๑ 2017 The American Society for Cell Biology. This article is distributed by The American Society for Cell Biology under license from the author(s). It is available to the public under an Attribution-Noncommercial-Share Alike 3.0 Unported Creative Commons License (http://creativecommons.org/licenses/ by-nc-sa/3.0)

"ASCB $®$ " and "The American Society for Cell Biology ${ }^{\prime}$ " are registered trademarks of The American Society for Cell Biology. 
Because student attrition is high during the first year of college, enhancing student academic success during the first year is often a primary focus of bridge programs (Chen, 2013). Firstyear student academic success at large institutions is mainly driven by student performance in high-enrollment introductory courses (Chen, 2013; Freeman et al., 2014). Many of these introductory courses have recently been transformed into student-centered, active-learning classrooms due to a growing body of literature demonstrating that it is a more effective way to teach (American Association for the Advancement of Science [AAAS], 2011, 2015; Freeman et al. 2014). In contrast to instructors predominantly transmitting information to students by lecturing during class, active-learning classrooms give students the opportunity to construct their own knowledge, often through group work with other students (Freeman et al., 2014). However, despite the increasing number of large introductory classes being taught using an active-learning approach (AAAS, 2015), it is unclear whether, and in what ways, bridge programs are preparing students to be successful in these activelearning classes.

As classrooms are transformed to become more student-centered, additional responsibility is placed on the student to direct his or her learning. Students can decide to what extent they will thoughtfully engage in active learning (e.g., choosing to deeply think through a clicker question vs. simply selecting an answer), and students working in groups often have to decide how they will approach an activity (e.g., choosing to divide up a group assignment or work on each question collaboratively). Despite the increased responsibility for students to guide their own learning in student-centered classrooms, there is relatively little known about what factors influence how students decide to approach active learning or whether students try to maximize their experiences in active learning. Some research suggests that instructor practices influence student behavior in active-learning classrooms. For example, students are significantly more likely to discuss their reasoning during peer discussion when instructors ask them to explain their reasoning (Knight et al., 2013). Furthermore, learning assistants asking questions, rather than answering questions, can elicit higher-quality student discussions (Knight et al., 2015). While these studies illustrate that instructor behaviors in the classroom can temporarily influence students' levels of engagement in active-learning activities, it is not clear whether these practices have longer-term impacts on how students will maximize their learning in future learning environments. The question remains: How can we empower students to independently maximize their own experiences in active learning and develop the ability to initiate a deeper level of engagement on their own?

In this study, we explored the impact of a 2-week Summer Bridge program on student attitudes and self-reported behaviors when engaging in active learning. While the primary goal of the Bridge program was to teach biology content to students and not to prepare students for active learning, the biology content in the program was taught using active-learning approaches. Through pilot interviews, we unexpectedly found that students who participated in the Bridge program had sophisticated views of active learning that warranted further exploration. We therefore set out to do an exploratory interview study to examine the impact of the Bridge program on student attitudes toward and approaches to active learning.
Our specific research questions were as follows:

1. How do Bridge students' perceptions of their active-learning experiences compare with the perceptions of students who were eligible for, but did not participate in the program (non-Bridge students)?

2. What strategies did Bridge students develop to maximize their active-learning experiences and how do these compare with strategies developed by non-Bridge students?

\section{BRIDGE PROGRAM AND INTRODUCTORY BIOLOGY COURSE DESCRIPTION}

This Summer Bridge program was developed and implemented at a large R1 research university in the southwestern United States. Institutional academic ability index scores were used to determine student eligibility for the program. Based on these index scores, which are a combination of high school grade point average (GPA) and Scholastic Aptitude Test (SAT) or ACT score, academically underprepared students are predicted to perform poorly in introductory biology and are at risk for ultimately not completing their first year at this institution (see the Supplemental Material). In an effort to help prepare these students so that they persist, students with index scores in the lowest quartile are placed into a refresher introductory biology course during their first semester of college. This refresher introductory biology course is a prerequisite for the standard introductory biology sequence. Any student who was placed into this refresher introductory biology course was eligible to participate in the Bridge program. Students were recruited through a combination of emails and in-person orientation events. Of the 107 students who were eligible to participate in the Bridge program, 28 students self-selected into the program, which had a maximum capacity of 30 students.

The main goal of the 2-week immersive Summer Bridge program was to improve the academic performance of students in their refresher introductory biology course so they would be more likely to persist as biology majors through their first year of college. As such, the focus of the program was to teach biological concepts that had been previously identified as challenging for students. The program's contact time was approximately 95 hours during the 2 weeks before Fall semester classes started; approximately 40 of those hours were focused on teaching biology content, and the rest of the time was dedicated to building community, exposing students to campus resources, introducing students to faculty research, and teaching general study strategies (see the Supplemental Material for an abridged schedule).

We implemented active-learning approaches in every biology lesson, because the literature suggests that this is a more effective way to teach biology concepts (Freeman et al. 2014). We used a variety of active-learning techniques (e.g., clicker questions, whiteboard work, worksheets, building models, creating skits). Students were asked to be metacognitive about their learning, including reflecting on the most important point and the most confusing point (e.g., muddiest point) of each lesson (Angelo and Cross, 1993; Tanner, 2012). Additionally, students were asked to engage in group work in every active-learning session. For each lesson, students were randomly assigned to work in a new group and had the opportunity to work with nearly every other student by the end of the 2-week program. We designed our own curriculum and focused 
on previously established challenging concepts in the refresher introductory biology course. We supplemented our curriculum with previously published active-learning exercises, including the "Fatherless Snake" for an exercise on meiosis and mitosis (Wright, 2014) and the "Mystery Tubes" for an exercise on the nature of science (University of California Museum of Paleontology, Berkeley, 2010).

At the end of the two-week program, Bridge students began their first semester at college in the refresher introductory biology course with all other students who had been eligible to participate in the program, but chose not to participate. There were 107 students enrolled in the refresher introductory biology course. The instructor of the refresher introductory biology course was not associated with the Bridge program but taught the course using active learning. Students in the refresher introductory biology course engaged in similar types of active-learning activities as the Bridge program (e.g., clicker questions, whiteboard work, worksheets) and were asked to participate in group work during almost every class period. Students were randomly assigned to work in small groups of two to three students and were assigned a new group about every 5 weeks. In total, students worked in three different groups throughout the semester. Bridge students were mixed in with non-Bridge students in these groups.

\section{METHODS}

We used interviews to probe student perceptions of active learning and group work (Wengraf, 2001). Halfway through the students' first semester in college, we conducted a set of semistructured interviews with a sample of seven Bridge students to explore their general perspectives about the Bridge program. These students were purposefully selected to be representative of genders, races/ethnicities, and academic abilities of students in the program (Patton, 2005). While preliminary interviews did not focus on active learning, we unexpectedly identified that student perceptions of active learning and group work warranted further exploration (see the Supplemental Material for interview questions). We then designed a new set of interview questions specifically focused on students' experiences in active learning and group work (see the Supplemental Material for interview questions). We were able to interview 26 of the 28 Bridge students at the end of their first term in college, upon completion of the refresher introductory biology course. As a comparison with the Bridge students, we recruited non-Bridge students who had completed the same refresher introductory biology course and had been eligible to participate in the Bridge program but chose not to enroll. We continued to recruit and interview non-Bridge students until we felt the data were saturated and no new themes were emerging with additional interviews (Morse et al., 2002).

During the interviews, the interviewer defined active learning and group work for the students before asking any interview questions using these terms. We adapted our definitions from the biology education literature (e.g., Freeman et al., 2014; Eddy, Brownell, et al., 2015; Eddy et al., 2015). Specifically, active learning was defined as in-class activities such as clicker questions and worksheets that students do independently or in a group and activities outside class such as reading or watching videos that provided the foundation for in-class discussions. Group work was described as occurring when a student worked with at least one other student in a biology classroom (see the Supplemental Material for interview protocol).

Interviews were transcribed and anonymized; pseudonyms were given to students to protect their identity. Using a constant comparative method (Glaser, 1965), one author (K.M.C.) identified emergent themes and active-learning strategies by simultaneously coding and analyzing the data from all Bridge student interviews (Taylor and Bogdan, 1998; Kolb, 2012). To establish coding reliability, we created a coding rubric and two independent raters (K.M.C. and M.A.) scored a subset of student responses and had a consensus estimate greater than $90 \%$ (Stemler, 2004), and one author (K.M.C.) continued to code the remaining Bridge interviews. Non-Bridge student interviews were immediately transcribed, coded, and analyzed upon completion to determine whether new themes or active-learning strategies emerged. No new active-learning strategies emerged; all new themes were identified within the first two interviews that we analyzed, and variability of code frequency appeared to be relatively stable by the analysis of the fourth interview (Guest et al., 2006). Therefore, we were confident that we had reached data saturation when eight interviews had been completed and code frequency was relatively consistent (Guest et al., 2006). All Bridge student interviews were recoded for new themes that emerged from the non-Bridge student interviews.

We illustrate our findings below, with quotes sampled from all of the interviews with Bridge and non-Bridge students. Some quotes were minimally edited for clarity by inserting clarification brackets or using ellipses to indicate excluded text.

A protocol for this study on human subject research is approved by Arizona State University's Institutional Review Board (00003820).

\section{RESULTS \\ Participants}

All of the students who we interviewed were enrolled in the refresher introductory biology course during their first semester of college. These students were all eligible for the Bridge program, but some chose to participate in the program while others did not. We interviewed 26 out of the 28 students (93\%) who participated in the Bridge program and eight non-Bridge students. None of the students reported experiencing active learning before coming to college. However, all students reported participating in group work during high school. Student demographic characteristics are shown in Table 1.

\section{Finding 1. Bridge Students Perceive That They Benefit More from Active Learning in Introductory Biology Than Students Who Did Not Participate in the Bridge Program} We were interested in Bridge students' perceptions of their active-learning experiences and how their perceptions compared with perceptions of students who did not participate in the program. We found that Bridge students perceived that they benefited more from active learning than non-Bridge students. Overwhelmingly, Bridge students reported that they understood the purpose of doing active learning and perceived that they maximized their active-learning experiences more than non-Bridge students in the refresher introductory biology course. 
TABLE 1. Demographic characteristics of Bridge and non-Bridge students, including student gender, race/ethnicity (described as majority [white or Asian student] or URM [Black, Latina, or Native American student]) and incoming academic ability score (calculated using student high school GPA or class rank and SAT or ACT score)

\begin{tabular}{lllc}
\hline & Gender & Race/ethnicity & Average academic ability score \\
\hline Bridge students & $65 \%$ female; 35\% male & $61 \%$ URM; 39\% majority & 99 \\
Non-Bridge students & $100 \%$ female & $63 \%$ URM; 37\% majority & 101 \\
\hline
\end{tabular}

Many Bridge students indicated that they perceived active learning to be important and valuable, which, in turn, seemed to enhance their experiences. Students specifically cited how their experiences during the Bridge program helped them see how useful active learning could be. For example, Mariana talked about how Bridge students seem to care more about active learning than non-Bridge students, and she perceives that this influenced the extent to which students benefited from participating in active learning.

\begin{abstract}
Mariana (Bridge): I think I get more out of active learning, because some [students in the refresher introductory biology course] don't take it serious and Bridge students, I always hear us saying, like, "Oh, what could the answer be?" We benefit from [active learning] more. I think it's because during Bridge we were shown to care about what you're learning. I think maybe that's why and the other students could care less about it. A lot of them complain, "Why do we always do clickerquestions?" They don't realize how beneficial it is, so I feel like we do have a different feel on certain things compared to the students who didn't have Bridge.
\end{abstract}

Interviewer: What does it mean to benefit more from active learning?

\section{Mariana (Bridge): I feel like I learn more.}

Another student, Gloria, explained that the Bridge program helped her to learn how to engage in active learning. Understanding how to maximize her experience in an active-learning classroom helped her realize why she was being asked to do active learning and the benefits she received from participating. Gloria compared her opinion with her perception of non-Bridge students who did not seem to understand the purpose of active learning and held negative or indifferent opinions of this pedagogical approach.

Gloria (Bridge): I think the other people who didn't participate in Bridge are more like, "Why are we doing active learning? This is stupid." I feel like me, personally being in Bridge, I understand the importance and how well active learning works when you do it right. I can see it makes sense and it helps me more. The other [students], they're just like, "Whatever," about it.

Gloria elaborated on what it means to "do [active learning] right."

Gloria (Bridge): Bridge taught me that participation is key. You need to have everyone involved and helping and talking instead of being like, "I don’t know," or, "Yeah, whatever you say." I know in Bridge we all went off of each other's ideas and were like, "What about this? What about that?" Questioned people's thinking instead of going along with what one person would say.

Amy echoed Gloria's thoughts and talked about how the Bridge program helped her learn how to take full advantage of active learning by thinking deeply about questions that she was trying to answer in class.

Amy (Bridge): I wasn't bitter about [doing active learning] like other [non-Bridge students], because I knew we needed the in depth responses to everything. A lot of people were not willing to do that, but Bridge taught me that, that's what you're supposed to be doing. You need to incorporate your thoughts and opinions on answers. We got to really think about what was taught.

Similar to many other Bridge students, both Amy and Gloria indicated that learning how to approach active learning helped them to maximize and understand the benefits from participating in active learning. Bridge students perceived that students who did not participate in the Bridge program did not understand the benefits of group work, a dominant component of active learning in the refresher introductory biology class, and were less likely to engage in peer discussions. However, Bridge students reported that they themselves had a more positive opinion of group work, because, even though most of them had come into the Bridge program with negative views of group work, they felt as though they learned well when working with other students during the Bridge program. For example, Lauren explained that she is able to solidify her conceptual understanding when she hears other people's ideas and understands the material better when she is able to teach other students.

Lauren (Bridge): I feel like a lot of people don't like group work, because they either think they do better off alone, or they're worried they're going to have group members that don't participate. I think the Bridge program helped me look at all of it, no matter what circumstance, in a way that if it's not perfect, the group work can be improved. The Bridge program definitely helped a lot.

Interviewer: What is your opinion of group work?

Lauren: Being able to talk with other people and being open to hearing other people's ideas really solidifies what I know. If I'm missing something, talking to other people really helps me. Also, teaching other people, so if someone doesn't understand, and I explain it to them, that helps me understand it better. 
Similar to Lauren, Mariana also perceived that non-Bridge students did not understand the purpose of participating in group work. She also explained that she views group work as useful because it helps her expand what she knows.

Mariana (Bridge): Most of the time [students who were not in Bridge] would complain around the table. They'd say, "Why do we always have to do group work?" They don't realize how helpful it is to work in a group.

Interviewer: Why do you think it's helpful to work in a group?

Mariana (Bridge): Because it's better to have another person's input than just your own. You could be wrong and the other person could be right, so having that other person helps you expand your knowledge.

The contrast between Bridge and non-Bridge students' perceptions of group work is corroborated by non-Bridge students, including Jayla, a non-Bridge student who did not see a benefit to working in groups. She explained that she felt as though she learned more during a traditional lecture than when engaging with other students.

Interviewer: Do you think you get more out of active learning than other students in introductory biology?

Jayla (non-Bridge): I feel like I got less out of [active learning]. I feel like I don't learn as much, I guess, in group work. The professor wasn't teaching enough, and it was just we were doing more group work. Whereas I learn more by the professor himself, by giving notes and lecturing on a topic, whereas in active learning, we only had to work with the students, I just felt like I needed the professor more than the students.

Similarly, another non-Bridge student, Olivia, highlighted how she felt as though she did better work by herself in comparison with working with other students. This was in direct contrast to Bridge students, like Lauren and Mariana, who felt that working with other students enhanced their learning.

Olivia (non-Bridge): Even though other students are helping me, I feel like I do better work by myself. I like working by myself. I think other students like working in groups better because they get the work done faster.

Although Olivia speculated that other students preferred working in groups to get work done faster, this was not what emerged from the Bridge student interviews. Bridge students, such as Lisa, highlighted that they appreciated group work because it was a chance to collaborate and hear other students' ideas. She also perceived that students who did not participate in the Bridge program, like Olivia and Jayla, did not seem to think that group work is important.

Lisa (Bridge): Maybe the problem is that the other kids didn't necessarily think group work was important going into [the refresher introductory biology course]. So they were kind of like, "I'm here to take my classes, do my own individual thing," but us Bridge kids we were like, "Dude, let's collaborate, let's figure this out together." So maybe [students who were not in Bridge] just didn't even have the idea that group work was important. We weren't very individual, like, Bridge kids weren't very individual. We were very, like, wanting to share ideas and wanting to accept other people's ideas. Other kids, it wasn't even part of their plan of action, so they didn't even have an idea of how to interact with the other students.

Not only did Bridge students talk more about collaboration in group work, they also seemed to view the purpose of active learning differently. Bridge students indicated that the focus of group work for them was to learn, as opposed to getting a grade. Interestingly, some Bridge students interpreted nonBridge students' focus on grades as detrimental to the overall learning experience in active learning. Both Luke and Daniella differentiate between participating in active learning to learn as opposed to participating to get a grade.

Luke (Bridge): I think some [non-Bridge students] are worried that in group work they were going to have to work harder to get the grade or it's going to mean they're all worried about their grades and stuff and not just learning [...] I don't really worry about my grade until the end of the semester, I just ignore it and try to learn a whole bunch of stuff.

Daniella (Bridge): I actually think about [active learning] as something that I can learn from because we're all acting with each other, but some students in [the refresher introductory biology course] just think about it as something to turn in and like get the grade, which is annoying because active learning helps actually a lot.

Bridge students perceived that they were not as gradefocused in group work compared with non-Bridge students due to how group work was implemented during the Bridge program. Group work during the Bridge program was not connected to specific grades, and students had opportunities to discuss and answer questions in a setting where there was less pressure on getting the right answer. One Bridge student, Gabriela, described being encouraged to think of new ideas as opposed to the right answer during group work in the 2-week program, because there was low risk for being wrong.

Gabriela (Bridge): We didn't have to come straight into college and have all that pressure. We had that transition during Bridge where it was OK to be wrong. That was really nice. The fact that there were no grades and the environment, and like instructors would say "this is low risk, don't worry about being wrong."

Another student, Luke, echoed this perception that the lack of grades assigned in the Bridge program allowed students the freedom to suggest wrong ideas and to learn for the sake of learning.

Luke (Bridge): In Bridge, 90\% of what we did was not worth points at all. All of that discussion, it's not like you are getting any points for it, there's no grade for it. Even if you had a spectacularly wrong answer, no one really cared [...] Bridge did a really good job of just doing like, here's how to learn for learning, not learning for a grade. It's different. 
In contrast to the Bridge students' focus on learning as opposed to getting grades, Jayla, a non-Bridge student, explained that she participates in active learning in order to get a good grade.

Interviewer: Talk to me about your level of participation in active-learning in [the refresher introductory biology class].

Jayla (non-Bridge): I always participate. Anything to get the assignment done and to get a good grade on it.

Overall, Bridge students' perceptions that they gained more from active learning compared with their peers were supported by the interviews of comparison non-Bridge students who perceived that they did not get anything more out of active learning or group work than other students in the course.

Interviewer: Do you think that you get more out of active learning than other students in your intro bio class?

Luciana (non-Bridge): I would say it's about even with everyone. I don't necessarily understand why, I guess.

To try to explore why there may be differences between the perceived benefits of group work and active learning between Bridge and non-Bridge students, we investigated whether Bridge students were approaching active learning with different strategies than their non-Bridge peers.

\section{Finding 2. The Majority of Bridge Students Use Distinct Strategies to Maximize Their Experience in Active Learning That Are Not Used by the Majority of Non-Bridge Students} Preliminary interviews with a subset of Bridge students led us to suspect that Bridge students may be using specific strategies to maximize their experiences in active-learning classrooms. We compared Bridge student interviews with non-Bridge student interviews to further understand whether Bridge student approaches to active learning were different from other students' strategies. We report out only themes that were described by the majority (at least 50\%) of students in either the Bridge and non-Bridge samples, because we want to focus on only the most prevalent themes in each group (Morse et al., 2002).

To avoid overreporting the number of strategies or falsely identifying a theme simply because we analyzed a higher number of Bridge interviews than non-Bridge interviews, we also analyzed a subset of eight randomly selected Bridge interviews and compared them with the eight non-Bridge students. We did not see any differences in the number of reported strategies by Bridge students with this subset, which led us to conclude that we were not overreporting strategies used by Bridge students.

We describe each strategy that emerged and provide representative quotes selected from all student interviews in Table 2. Seven distinct active-learning strategies were identified from the interviews (Table 2). All seven strategies were reported by the majority of Bridge students, and only three strategies were reported by the majority of non-Bridge students. The strategy/ strategies reported out by each individual student are reported in Supplemental Figure S1. The majority of Bridge students and the majority of non-Bridge students reported 1) asking questions for clarification or superficial understanding, 2) leading or delegating during group work, and 3) encouraging other students to participate in active learning in order to benefit oneself. Four additional strategies emerged from the majority of Bridge students but not from the majority of non-Bridge students (Table 2). These active-learning strategies included 1) being open-minded or optimistic during group work, 2) intentionally sharing thoughts with others to enhance discussion, 3) deeply engaging in active learning, and 4) encouraging other students to participate in active learning for those other students' benefit.

Strategies reported out by the majority of Bridge students tended to align with best practices for active learning, and we considered them more sophisticated strategies. For example, sharing one's thoughts and ideas with others and encouraging other students to participate in group work have both been described as essential elements of cooperative learning (Johnson et al., 1991; Tanner et al., 2003). Notably, Bridge students attributed learning these strategies to the Bridge program. For example, Amy illustrated that she tried to move away from superficially engaging to deeply engaging in active learning specifically because of her experience with active learning in the Bridge program. She went on to explain that being required to work in groups where all students participated and were asked to share ideas really helped her understand how to approach active learning.

Amy (Bridge): Bridge helped me really know what I should be doing with active learning, and what's expected of me with active learning. For example, it's important to discuss with my group, and that we really think out our answers and not just put down what they want to hear, but really go through it and give a detailed answer. It's important to think about each question.

Interviewer: What about the Bridge program helped you to learn that?

Amy (Bridge): Just the way [the Bridge program] was set up, we had to talk to everyone. It wasn't just filling out a worksheet or something. We always were asked to work as a group and there wasn't just one person doing it. We just had to do group work so much that I really knew what to do when talking to other people. I knew how to share my ideas with everyone.

Bridge students also mentioned that, although they had experienced group work in high school, they did not learn to share their thoughts or ideas until they were in the Bridge program. For example, Samantha talks about how she learned to speak up for herself during the Bridge program but had trouble articulating what helped her learn how to do so. She acknowledged that active-learning activities, such as board work, were influential and switching groups may have helped, but then highlighted that the instructors and environment of the Bridge program likely contributed.

Samantha (Bridge): I learned how to actually speak up for myself. Before Bridge I was just, "Oh, yeah, we can do 


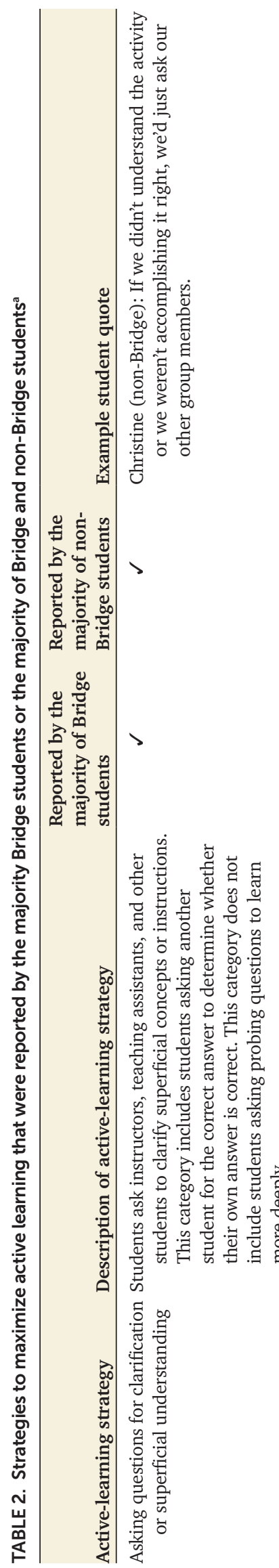

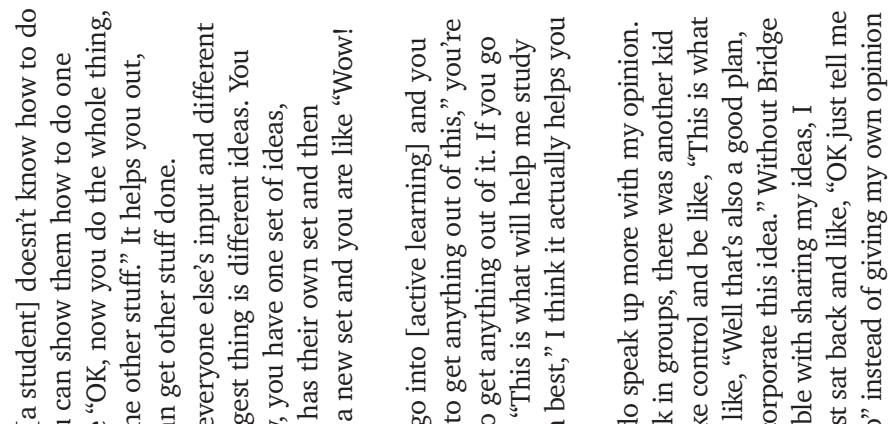

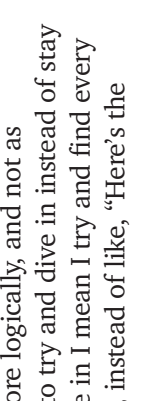

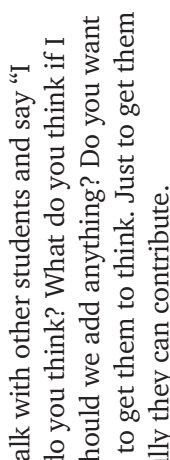

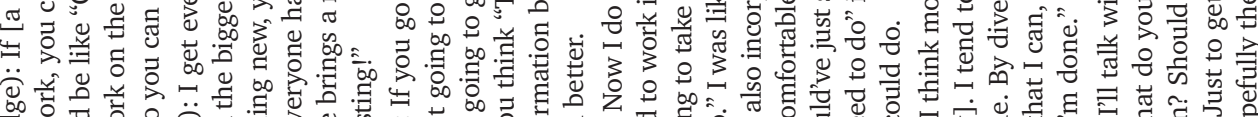

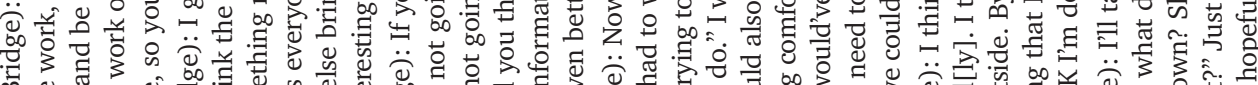

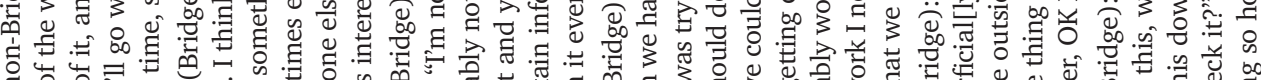

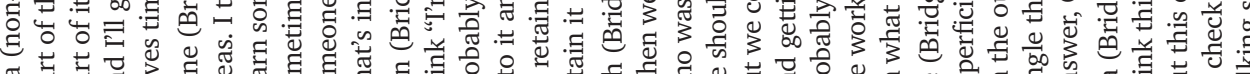

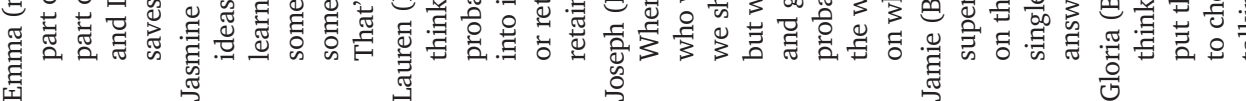
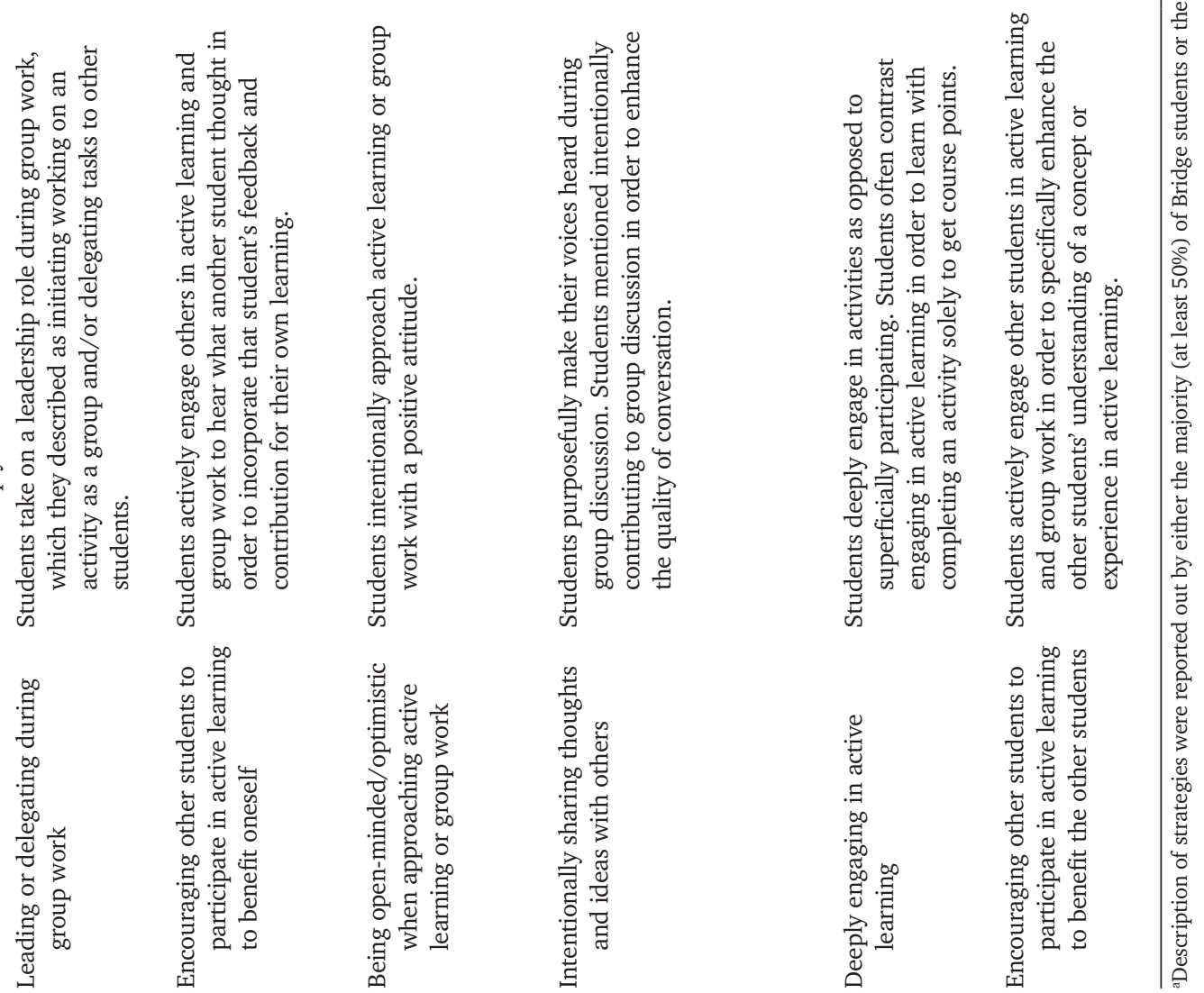
that." Now, I'm actually really outgoing on my thoughts and ideas.

Interviewer: How did you learn to speak up for yourself?

Samantha (Bridge): I think it would have been the board work and all the learning concepts that we had to write on there. I actually learned how to talk. I don't know. I think it might have been-I think if anyone else would have taught [the program], it would have been different. I think, it's the environment [of Bridge], maybe. Because we had switched so many groups, we all knew each other [by] the end. At the end, I know we were really interacting with each other and we all knew each other. Maybe it would have been the environment or it was the group. I don't know.

Samantha's inability to pinpoint what aspect of the Bridge program led to her understanding of the active-learning strategy was echoed by other Bridge students. So while the majority of Bridge students reported these more sophisticated strategies for maximizing their active-learning experience and attributed learning these strategies back to the Bridge program, they struggled with articulating what specific aspect of the Bridge program led to their understanding of these strategies. This is likely because there is not one component of the Bridge program that is leading to the development of these strategies but a synthesis of multiple aspects of the program.

\section{Finding 3. Bridge Students Take an Equitable Approach to Group Work}

When Bridge students were asked about why they chose to participate in the Bridge program, they all explained that they were motivated to participate in the program by the benefits that they would personally receive from the program. However, the majority of Bridge students mentioned that they engaged other students in active learning for the benefit of other students in the group. Interestingly, not one of the non-Bridge students mentioned using this strategy (see Supplemental Table S1).

During the interviews, we did not specifically ask students about the experiences of other students during group work. Therefore, we were interested in whether this equitable mindset was unique to the Bridge students and reanalyzed both Bridge and non-Bridge student interviews for equity-related themes. We found that $65 \%$ of Bridge students acknowledged thinking explicitly about equity or taking an equitable approach when engaging in group work and active learning. In contrast, we found that none of the non-Bridge students talked about taking equitable approaches to active learning. Specifically, we identified three equity-related themes from the interviews (Table 3). We found that only non-Bridge students held a student deficit model of their group mates' participation in group work; Bridge students did not hold this conception. Further, only Bridge students felt as though it was their responsibility to help other students learn during group work, and not a single non-Bridge student reported this idea. Finally, we found that only Bridge students and no non-Bridge student monitored equity in participation during group work in the refresher introductory biology course (Table 3 ). While we cannot extrapolate these findings to all students who did not participate in the program, we use student interview quotes to highlight the
TABLE 3. Three equity-related themes emerged from the interviews and were held by either only Bridge students or only non-Bridge students

\begin{tabular}{|c|c|c|}
\hline Equity-related theme & $\begin{array}{c}\text { Only held by } \\
\text { Bridge students }\end{array}$ & $\begin{array}{c}\text { Only held by } \\
\text { non-Bridge students }\end{array}$ \\
\hline $\begin{array}{l}\text { Student deficit model of } \\
\text { group-mate participation }\end{array}$ & & $\checkmark$ \\
\hline $\begin{array}{l}\text { Responsibility to help other } \\
\text { students learn }\end{array}$ & $\checkmark$ & \\
\hline $\begin{array}{l}\text { Monitoring equity during } \\
\text { group work }\end{array}$ & $\checkmark$ & \\
\hline
\end{tabular}

different ways that students in the same refresher introductory biology course think about equity.

Student Deficit Model of Group-Mate Participation: Held by Non-Bridge Students, but Not Bridge Students. Non-Bridge students expressed a student deficit model of group mates' willingness to participate in group work wherein they assumed that silence or nonparticipation from a group member was because that student did not want to participate. Further, non-Bridge students highlighted that other students often have a negative impact on overall group productivity, because they work more slowly or do not complete as much work overall.

Jayla (non-Bridge): Sometimes you get paired with people who really don't know what they're doing and it makes it harder to get the assignment done. Sometimes they're lazy and don't want to do anything. In those situations I just kind of did the work myself. I let them do their own thing and then I would just do my own, basically just get the work done by myself.

Chloe (non-Bridge): When we got switched to different groups, I was doing more of the work while the other person wasn't, they were doing their own thing, just letting me do the work because they didn't want to do the work.

In contrast, Bridge students had very different interpretations of other students not participating. Bridge students thought that perhaps their group members might be shy or not know how to participate. Bridge students seemed to assume the best of the other students in the class as opposed to assuming they are so-called social loafers, students who let other students in the group do all the work (Pfaff and Huddleston, 2003).

Liam (Bridge): If I don't say, "All right, what do you think about this?" then [my partner] is just going to sit there. I'll make the first move because it's not really a big deal, it's just maybe he's a little shyer than I am.

Gabriela (Bridge): I try to make sure that I'm asking [other students] questions, because even though I think I'm shy, there's probably someone shyer than me that just lets someone take over if they're not asked and they might not think to talk. They might think to just let someone else talk.

Another Bridge student, Anthony, explained that he had a student deficit mind-set when he first started the Bridge program. However, working with different students during the 
Bridge program helped him learn to avoid making assumptions about other students' intelligence.

Anthony (Bridge): I learned in Bridge to not judge a book by its cover. At first I noticed that a lot of people would just sit there and not really talk or do anything. I'd be like, "Well, I don't want to work with them." Then I ended up having to work with them and it turns out that I'm like, "Wow! You really know your stuff, this person is kind of a cool person." Bridge taught me to just never judge a book by its cover. You get [to class] and you work with them and you just talk to them.

During the refresher introductory biology course, students were asked to work in three different groups throughout the semester. Therefore, non-Bridge students also had the opportunity to become more open-minded about other students in the class, but these interviews suggest that they did not develop this mind-set. In addition to changing groups three times during the refresher introductory biology course, students during the Bridge program were asked to work with a new, randomly assigned group of students approximately 20 times; the difference in the number of different group experiences may have contributed to the difference in equity mind-set between Bridge and non-Bridge students.

Responsibility to Help Other Students Learn: Held by Bridge Students, but Not Non-Bridge Students. Bridge students felt as though it was their responsibility to give other students the opportunity to participate and to help encourage other students to engage in active learning. If one of their group mates was not talking, Bridge students felt as though they needed to provide the space for that student to participate.

Lauren (Bridge): I try really hard not to do all of the work so that nobody else is getting anything out of it. Also, I found that it's really easy for me to coordinate things, and get people thinking so we can all get something out of group projects.

Liam (Bridge): Basically everything that we did in [the refresher introductory biology course], you had to use your partner. If you didn't, then it's really only hurting them, but if you're doing all the work and you're not getting any input from your partner, then they might be lost going into the test or something. I think that's the advantage that [Bridge students] have over [non-Bridge students], is that we realize that, "OK me and my partner should both be able to come out of this with the same amount of information. We should both be able to understand the concept in almost the same way."

Further, Bridge students expressed that, because they had a head start on learning biology in the Bridge program, they felt as though they had a certain amount of responsibility to help other students learn.

Brian (Bridge): I kind of would be more sympathetic towards some people who didn't understand the lessons because I'd already gone through this [content] in Bridge and I already know [the information]. It would kind of be easy for me to help them and to understand their situation.
Amy (Bridge): Because of all the information we went over in Bridge I had a better understanding of a lot of the concepts that we were going over in [the refresher introductory biology course]. I was able to bring that in and help other people.

This was in contrast to non-Bridge students, none of whom held conceptions that they needed to maximize other students' learning experiences. This was exemplified by Emma, a nonBridge student who perceived that it was not her responsibility to help other students learn.

Emma (non-Bridge): A bad group would be people who just talk about other things other than biology.

Interviewer: Do you do anything to handle those situations?

Emma (non-Bridge): I'll be like "hey guys, can you please do your work." If that doesn't work, then it's just kind of- that's not my responsibility. More learning for me, I guess.

Monitoring Equity during Group Work: Held by Bridge Students, but Not Non-Bridge Students. Bridge students described explicitly thinking about issues of equity in participation in active learning. During group work in the Bridge program, instructors often assigned roles for each student in the group, including speaker, recorder, and equity monitor (Mitchell et al., 2003; Tanner, 2013). An equity monitor is a member of the group who ensures that all members have contributed, and if someone has not contributed, the equity monitor is tasked with asking that person to contribute (Tanner, 2013). Luke, a Bridge student, described how he continued to assume the role of equity monitor in the refresher introductory biology course even after the program ended, notably when the instructor in the refresher introductory biology class did not assign it.

Luke (Bridge): I keep track of who has talked and had input. That was a Bridge thing, that was one of the roles in the first four or five days, make sure everyone has talked and had input. I just liked doing that job when I had it so I just kept doing that in [the refresher introductory biology course] even when it wasn't my job. Asking "Well what does this person think?"

Daniella described how the Bridge program taught her to help other students by encouraging them to be active in their own learning and keeping track of their participation in the group.

Daniella (Bridge): If someone is not participating in [the refresher introductory biology class], I feel like we should let them participate, like keep asking them questions, and be like "Hey, participate in this." The instructors of Bridge told us to have someone that is looking out for everyone participating [an equity monitor] and some of us were really quiet in the beginning of the Bridge, so I feel that's good.

Bridge students indicate that they sometimes thought about equity, not only for a final outcome such as learning or a grade, but just for the sake of equity. 
Gloria (Bridge): I always want to be open to other people and make them feel comfortable in a group setting, so that they can want to work in group settings not only right now, but in the future [...] I always want to feel open to what others have to say and really give them my attention, rather than being rude.

Another Bridge student, Anthony, talked about the importance of getting input from both students in a group, because the work will be turned in with both of their names on it. It is not meant to be only the ideas of one person, it is meant to be the group output, and that group output should be equitable.

Anthony (Bridge): If there's a question, we come up with an answer. Not just "Oh, hey this is the answer" or, "Hey, I think this is the answer, do you agree or do you disagree?" instead, we are collectively coming up with the answer. It's not one person doing it. There are two name lines. Two people with two names.

These Bridge student responses are in direct contrast with the responses from the interviewed non-Bridge students. The non-Bridge students seemed to take an individualized approach to learning and did not consider the other students' learning. Jayla suggested that if other students did not know the answer, then she could not help them.

Jayla (non-Bridge): One drawback to group work is when you're working with someone that just doesn't know what they're doing. Because then how do you help them and how can they help you if they don't understand what's going on? Then you're solely working by yourself basically.

A non-Bridge student, Christine, became frustrated with students who she perceived as lazy or did not want to work on the specific activity. She indicated that she would try initially to get the group back on task, but that ultimately their participation in the group was not her concern.

Christine (non-Bridge): Sometimes in your group there are lazy people, people who don't share work, don't do any work, maybe sometimes they talk too much too.

Interviewer: Do you have any specific strategies to handle those situations?

Christine (non-Bridge): I would tell them "Let's finish so we can get out early." Maybe I'll tell them to focus, maybe I can do the work myself, or if someone else is actually willing to listen and do the work and then I can work with them instead of those people that are going to talk.

\section{DISCUSSION}

As students transition from traditionally taught high school courses to active-learning college classrooms, they are faced with more opportunities to direct their own learning and tasked with deciding how to approach active-learning activities. Owing to increased interactions among students in active-learning classrooms, students also have greater influence over other students' participation and learning (Eddy, Brownell, et al., 2015).
The goal of this study was to explore Bridge student perceptions of active learning and group work and to examine whether students had developed strategies to approach active learning. To probe whether Bridge student conceptions and strategies were influenced by their participation in the Bridge program, we compared their thoughts with the thoughts of students who had been eligible for the program but did not participate. We found that Bridge students perceived greater gains from group work and active learning in their introductory biology course than non-Bridge students. Additionally, a distinct set of sophisticated active-learning strategies were reported out by the majority of Bridge students but not by the majority of non-Bridge students, including being attentive to equity in student participation.

We did not intentionally set out to teach students strategies to maximize their active-learning experiences in the summer Bridge program; these data were unexpected findings. Therefore, we were unable to systematically evaluate which aspects of the Bridge program led to these student gains. However, using the published literature on active learning and our own experience as instructors of the program as a lens to evaluate these findings, we can hypothesize why Bridge students may feel as though they benefited more from active learning and developed more strategies to enhance their experiences.

\section{Why Bridge Students Perceived That They Maximized Active Learning}

One explanation for why Bridge students developed additional strategies to maximize their active-learning experience is that they simply had more exposure to active learning than nonBridge students. Bridge students had an immersive experience in active learning totaling approximately 40 hours before starting the refresher introductory biology course. Perhaps this additional exposure to active learning gave Bridge students more concentrated time to develop these strategies.

An alternative explanation was that Bridge students were explicitly told of the value of active learning, and this did not occur in the refresher introductory biology course. Bridge students mentioned that they felt as though they benefited more from active learning than other students who did not participate in the program because they better understood the importance of participating in active learning. When Bridge students were asked why they thought doing active learning was important, they mentioned how instructors of the Bridge program had talked explicitly about the benefits of participating in active learning. This "instructor talk" has been suggested as a way to reduce student resistance to active learning (Seidel and Tanner, 2013). In fact, we devoted time during the first day of the program to show students that published research informed our pedagogical choices. In contrast, students reported that the instructor of the refresher introductory biology course never discussed the benefits of doing active learning with the class, so non-Bridge students may never have heard about possible benefits to participating in active learning. We hypothesize that this explicit instructor talk about the value of active learning during the Bridge program may have contributed to some of the differences in Bridge and non-Bridge student attitudes toward active learning.

During the program, we also encouraged students to be metacognitive about their own learning. We asked students to 
think about how they approach their own learning, which has been proposed as a useful strategy in developing students as biologists (National Research Council, 2000; D'Avanzo 2003; Crowe et al., 2008; Tanner 2012). Bridge students indicated that the skills of identifying the most important points of biology lessons during the Bridge program helped them to think about the most important points during the lessons in the refresher introductory biology course. This metacognition about learning was apparent throughout the Bridge student interviews, especially when students described purposefully engaging deeply in active learning as opposed to completing tasks in order to receive points. Student metacognition has been proposed as a theoretical background explaining the mechanisms of active learning (Vos and De Graaff, 2004). Therefore, we suspect that encouraging students to be metacognitive about their learning during the Bridge program may have contributed to how Bridge students approach active learning.

The small size of the Bridge program may also have contributed to the development of active-learning strategies. The size of the program allowed instructors to closely monitor group work; instructors were able to facilitate group dynamics and scaffold student experiences to maximize their learning outcomes. If a student was dominating a discussion, we often reminded the student that sometimes the quietest people have the best ideas. Conversely, if a student was disengaged from the discussion, we asked the student to explain what he or she was thinking. Perhaps we were able to reinforce participation frequently enough in the program so that students were able to self-monitor their participation when they transitioned into the setting of the larger refresher introductory biology course.

Further, in the Bridge program, we intended to create a community where it was safe to be wrong. We stressed the importance of sharing out ideas and encouraged all students to participate in every activity. We often encouraged students to share ideas, even if they suspected that an idea might not be correct. We hypothesize that the process of realizing the importance of hearing and sharing out ideas, even incorrect ideas, influenced how Bridge students approached active learning. Furthermore, we suspect that the opportunity to practice these strategies in a safe space contributed to Bridge students' willingness to engage other students in active learning and share their thoughts and ideas with a group.

\section{Why Bridge Students Seem to Be More Attentive to Equity}

Perhaps the most surprising outcome from the program is the Bridge students' comments about equity in group work and their concern for other group members. In stark contrast to non-Bridge students, Bridge students were more aware of their potential impact on other students' learning and frequently referenced trying to help other students maximize their learning experiences. It is important to note that Bridge students did not work exclusively with other Bridge students in the refresher introductory biology course; they were assigned to work in three different groups throughout the semester that were a mix of non-Bridge students and Bridge students. So when they discussed helping other students, it is unlikely to be an artifact of working exclusively with only Bridge students.

As instructors of the program, we set out to create an equitable classroom environment (Tanner, 2013), but we did not expect students to develop skills to promote equity in other class- rooms. However, we hypothesize that the combination of being explicit in our language about equity (Seidel et al., 2015) and using evidence-based approaches to promote equity in the Bridge program (Tanner, 2013) may have influenced the way Bridge students think about equity and other students' learning.

Throughout the program, we used explicit instructor talk to explain the importance of creating an equitable classroom environment (Seidel et al., 2015). For example, we often reminded students that it is important to hear all students' opinions, that a quiet student may need structured time to participate, and that collaboration is essential in science. Some students, like Jasmine, mentioned that they picked up on what instructors said, which changed how they approached group work.

Jasmine (Bridge): Before Bridge I was a "to myself" kind of person, I would do things myself and was like, "I don't care what you think." Then everything was group work. When the instructors of Bridge were explaining it, "We do need group work to do science. We have multiple different ideas. There will be people who have a different set of ideas," that's when my mind changed.

In active-learning classrooms, students may realize that their success can depend on the contributions and success of their peers, which is called positive interdependence. To create positive interdependence, faculty can design tasks that require insight and effort from more than one person, building in the need to be conscious of how the other person is doing in the group (Tanner et al., 2003). Bridge students reported that challenging and open-ended tasks in the Bridge program, such as the "Mystery Tubes" exercise helped with this.

Daniella (Bridge): I think I learned how to work with different people because everyone has a different way of just getting to the question, getting the answer. I think that's really good because sometimes my way may not be the best way to get to the question and answers so I think that was good, it was very good. Like working on the ["Mystery Tubes"]. We all had different ideas at the end because everyone came up with the same solution in different way, so I think that was one of the things that helped me learn that.

We also structured active learning and group work to be attentive to inequities in participation. Structuring group work is not the same as simply putting students in groups; we were purposeful about equitable student participation through the use of assigned roles. Using roles such as "recorder" and "monitor" has previously been correlated with increased positive perceptions about group work (Mitchell et al., 2003) and has been recommended as a way to create more equitable environments in college biology courses (Tanner, 2013). The instructor of the refresher introductory biology course did not assign roles during group work. However, some Bridge students, like Luke and Daniella, explained that they continued using the role of equity monitor in the refresher introductory biology course, even though it was not assigned. Although it is unlikely that nonBridge students explicitly understood the benefits of structuring group work in this way, they may have benefited from experiencing more equitable group work when Bridge students carried on in the role of equity monitor during the refresher introductory biology course. 
Teaching students to value the opinions of others and equipping them with strategies to create equitable learning experiences in their classrooms could be a powerful step in creating a more inclusive community of scientists, particularly as we transition our undergraduate science courses to be more student centered. Could these equitable mind-sets observed in these introductory students persist throughout their academic careers? Teaching students to structure equitable environments themselves may be a sustainable and effective way to create a more diverse and inclusive future scientific community.

\section{Priming Incoming Students to Maximize Their Active-Learning Experiences and Promote Equity in the Classroom}

This study suggests that Bridge programs can prepare students to maximize their active-learning experiences in biology. We suspect that pairing a highly structured active-learning environment with explicit instructor talk could help students develop strategies to maximize their learning. More specifically, conveying the importance of participating in active learning and how to engage in active learning could have a positive effect on student attitudes toward active learning, especially if they are experiencing active learning for the first time. In addition to helping students to maximize their own experiences in active-learning classrooms, instructors may also be able to help students maximize other students' learning. Explicit instructor talk about the importance of encouraging all students to participate in group work could change the way some students approach working with others, resulting in more equitable student contribution.

We propose that institutions should consider adopting active-learning training for students to help prepare them for their active-learning courses. Many of the factors that we suspect may contribute to Bridge students' gains are not unique to summer bridge programs and could potentially be incorporated into introductory biology courses or supplementary firstyear experience courses. For example, biology instructors can explain why they choose to teach in an active-learning way to help students understand the value of active learning. Instructors can also structure their courses to encourage students to be metacognitive about their own learning. For example, instructors can implement the muddiest point exercise (Angelo and Cross, 1993; Tanner, 2012) to help students identify the concepts with which they are struggling the most. Furthermore, instructors can be explicit about the importance of working in groups and assign roles during group work to maximize student participation and attention to equity. However, the benefit of a summer bridge program is that it can serve as a vehicle to prepare students to maximize their active learning before they even begin college. More broadly, we suggest that positively priming students to maximize their active-learning experiences can enhance their experiences in future activelearning classrooms.

Finally, our study also suggests that we can prime students to maximize the active-learning experience of other students. In priming students to be attentive to inequities in participation in active learning and to feel a sense of responsibility to help other students learn, we could potentially create equitable classrooms from the ground up, with students working together to foster one another's learning.

\section{Limitations}

The students in this study transitioned from the Bridge program into a refresher introductory biology course that lacked structures and pedagogical strategies that may have created a more optimal active-learning environment for all students. For example, students reported that the instructor of the refresher introductory biology course did not explain why he chose to teach in an active-learning way and did not structure group work to maximize student participation. Therefore, in this paper, we documented the benefits of a Bridge program when students transition into a potentially suboptimal learning environment; further research is necessary to examine the benefits of a Bridge program in differently structured, and perhaps more optimal, active-learning classrooms.

Students self-selected into the Bridge program; the differences that we are observing in their strategies of maximizing active learning may reflect a self-selection bias in student motivation (Brownell et al., 2013). However, advertisements for the Bridge program did not mention active learning or group work. Therefore, it is unlikely that students enrolled in the program because they were interested in participating these particular learning approaches. In fact, all students reported that they had no prior exposure to active learning and were resistant to both active learning and group work at the beginning of the program. While Bridge students did not have more positive perceptions of active learning or group work upon entering the program, it is possible that students who enroll in early-start programs may be more motivated to do well in college, which may have contributed to Bridge student conceptions and experiences with active learning. Future research should explore the conceptions of randomized students into the Bridge program to account for self-selection bias.

We did not videotape the summer Bridge classes, so it is impossible to characterize the specific instructor talk during that time. We can only rely on student and instructor recollections of the Bridge program and what was said, which we acknowledge may be incomplete or biased. However, we predict that students underestimated the extent of the instructor talk, because they are likely to have forgotten specific comments that program instructors made.

A possible limitation to this study is that we only interviewed eight non-Bridge students as a comparison group. While small, it is not uncommon to use sample sizes such as this in qualitative research (Couch and McKenzie, 2006). More importantly, the data were saturated with these eight students, and no new ideas were emerging. Another possible limitation was that all of these non-Bridge students were female. Gender did not seem to impact Bridge student responses, and when we examined the responses of female Bridge students and female non-Bridge students, we found similar patterns as when we used the entire Bridge data set.

This study exclusively focuses on student perceptions of active learning and group work. We are in the process of tracking student retention from the program and hope to report on this longitudinal data in a subsequent article.

\section{CONCLUSION}

In this interview study, we unexpectedly found that a summer Bridge program positively impacted student attitudes and self-reported behaviors in active learning in contrast to students 
who were eligible but did not participate in the program. This indicates that perhaps we can prime students to maximize their own active-learning experiences. Further, we found that Bridge students exhibited concern for other students' participation in group work in introductory biology. This may be an untapped approach for training the next generation of biologists to be more equitable as a means to promote a more diverse and inclusive biology community.

\section{ACKNOWLEDGMENTS}

We thank the Bridge and non-Bridge students for talking with us about their thoughts about active learning. We thank Sarah Eddy, Liz Barnes, and Christian Wright for their thoughtful feedback on the article. We also acknowledge Miles Orchinik and Liz Barnes for their contribution to the development and implementation of the Summer Bridge program. This Summer Bridge program was financially supported by the College of Liberal Arts and Sciences at Arizona State University, and special thanks go to Paul LePore, Michele Daley, Grace Fama, and Scot Schoenborn.

\section{REFERENCES}

Boldface names denote co-first authors.

Ackermann SP (1991). The benefits of summer bridge programs for underrepresented and low-income students. Coll Univ 66, 201-208.

American Association for the Advancement of Science [AAAS] (2011). Vision and Change in Undergraduate Biology Education: A Call to Action, Washington, DC. http://visionandchange.org/files/2013/11/aaas-VISchange -web1113.pdf (accessed 19 March 2015).

AAAS (2015). Vision and Change in Undergraduate Biology Education: Chronicling Change, Inspiring the Future, Washington, DC. http:// visionandchange.org/files/2015/07/VISchange2015_webFin.pdf (accessed 28 March 2015).

Angelo AT, Cross KP (1993). Minute paper. In: Classroom Assessment Techniques: A Handbook for College Teachers, San Francisco: Jossey-Bass, 148-153.

Brownell SE, Kloser MJ, Fukami T, Shavelson RJ (2013). Context matters: volunteer bias, small sample size, and the value of comparison groups in the assessment of research-based undergraduate introductory biology lab courses. J Microbiol Educ 14, 176-182.

Buck CB (1985, February). Summer bridge: a residential learning experience for high risk freshmen at the University of California, San Diego. Paper presented at the Annual Meeting of the National Conference on the Freshman Year Experience, Columbia, SC.

Cabrera NL, Miner DD, Milem JF (2013). Can a summer bridge program impact first-year persistence and performance? A case study of the New Start Summer Program. Res High Educ 54, 481-498.

Chen X (2013). STEM Attrition: College Students' Paths into and out of STEM Fields. Statistical Analysis Report (NCES 2014-001), Washington, DC: National Center for Education Statistics.

Couch M, McKenzie H (2006). The logic of small samples in interview-based qualitative research. Soc Sci Inform 45, 483-499.

Crowe A, Dirks C, Wenderoth MP (2008). Biology in Bloom: implementing Bloom's taxonomy to enhance student learning in biology. CBE Life Sci Educ 7, 368-381.

D'Avanzo C (2003). Application of research on learning to college teaching: ecological examples. BioScience 53, 1121-1128.

Eddy SL, Brownell SE, Thummaphan P, Lan MC, Wenderoth MP (2015). Caution, student experience may vary: social identities impact a student's experience in peer discussions. CBE Life Sci Educ 14, ar45

Eddy SL, Converse M, Wenderoth MP (2015). PORTAAL: a classroom observation tool assessing evidence-based teaching practices for active learning in large science, technology, engineering, and mathematics classes. CBE Life Sci Educ 14, ar23.

Freeman S, Eddy SL, McDonough M, Smith MK, Okoroafor N, Jordt $H$ Wenderoth MP (2014). Active learning increases student performance in science, engineering, and mathematics. Proc Natl Acad Sci USA 111 $8410-8415$

Garcia P (1991). Summer bridge: improving retention rates for underprepared students. J First-Year Exp Stud Transit 3, 91-105

Glaser BG (1965). The constant comparative method of qualitative analysis Soc Probl 12, 436-445.

Guest G, Bunce A, Johnson L (2006). How many interviews are enough? An experiment with data saturation and variability. Field Methods 18, 59-82.

Johnson DW, Johnson RT, Smith KA (1991). Active Learning: Cooperation in the College Classroom, Edina, MN: Interaction Book Company.

Knight JK, Wise SB, Rentsch J, Furtak EM (2015). Cues matter: learning assistants influence introductory biology student interactions during clicker-question discussions. CBE Life Sci Educ 14, ar41.

Knight JK, Wise SB, Southard KM (2013). Understanding clicker discussions: student reasoning and impact of instructional cues. CBE Life Sci Educ 12 645-654.

Kolb SM (2012). Grounded theory and the constant comparative method: valid research strategies for educators. J Emerg Trends Educ Res Policy Studies 3, 83.

Mitchell S, Woloshyn V, Elliott A (2003). Promoting cooperative learning in the classroom. Brock Educ 12, 23-39.

Morse JM, Barrett M, Mayan M, Olson K, Spiers J (2002). Verification strategies for establishing reliability and validity in qualitative research. Int $J$ Qual Meth 1, 13-22.

Murphy TE, Gaughan M, Hume R, Moore SG (2010). College graduation rates for minority students in a selective technical university: will participation in a summer bridge program contribute to success? Educ Eval Pol Anal $32,70-83$

National Research Council (2000). How People Learn: Brain, Mind, Experience, and School, Washington, DC: National Academies Press.

Patton MQ (2005). Qualitative Research, Hoboken, NJ: Wiley.

Pfaff E, Huddleston $P$ (2003). Does it matter if I hate teamwork? What impacts student attitudes toward teamwork. J Marketing Educ 25, 37-45.

Seidel SB, Reggi AL, Schinske JN, Burrus LW, Tanner KD (2015). Beyond the biology: a systematic investigation of noncontent instructor talk in an introductory biology course. CBE Life Sci Educ 14, ar43.

Seidel SB, Tanner KD (2013). "What if students revolt?"-considering student resistance: origins, options, and opportunities for investigation. CBE Life Sci Educ 12, 586-595.

Stemler S (2004). A comparison of consensus, consistency, and measurement approaches to estimating interrater reliability. Pract Assess Res Eval 9(4), 1-11

Stolle-McAllister K (2011). The case for summer bridge: building social and cultural capital for talented black STEM students. Sci Educ 20, 12-22.

Strayhorn TL (2011). Bridging the pipeline: increasing underrepresented students' preparation for college through a summer bridge program. Am Behav Sci 55, 142-159.

Tanner KD (2012). Promoting student metacognition. CBE Life Sci Educ 11 113-120.

Tanner KD (2013). Structure matters: twenty-one teaching strategies to promote student engagement and cultivate classroom equity. CBE Life SCi Educ 12, 322-331.

Tanner KD, Chatman LS, Allen D (2003). Approaches to cell biology teaching: cooperative learning in science classrooms-beyond students working in groups. CBE Life Sci Educ 12, 322-331.

Taylor SJ, Bogdan R (1998). Introduction to Qualitative Research Methods: A Guidebook and Resource, 3rd ed., New York: Wiley

Terenzini PT, Rendon LI, Upcraft ML, Millar SB, Allison KW, Gregg PL, Jalomo $\mathrm{R}$ (1994). The transition to college: diverse students, diverse stories. Res High Educ 35, 57-73.

Tomasko DL, Ridgway JS, Olesik S, Waller RJ, McGee MM, Barclay LA, Harkin KT, Upton J (2013). Impact of summer bridge programs on STEM retention at the Ohio State University. In Proceedings of the 2013 ASEE 
North-Central Section Conference, Washington, DC: American Society for Engineering Education, 1-13.

University of California Museum of Paleontology, Berkeley (2010). An Understanding Science Lesson: Mystery Tubes. http://undsci.berkeley.edu/ lessons/mystery_tubes.html (accessed 14 April 2013).

Vos H, De Graaff E (2004). Developing metacognition: a basis for active learning. Eur J Eng Educ 29, 543-548.

Walpole M, Simmerman H, Mack C, Mills J, Scales M, Albano D (2008). Bridge to success: Insight into summer bridge program students' college transition. J First-Year Exp Stud Transit 20, 11-30.
Wengraf T (2001). Qualitative Research Interviewing: Biographic Narrative and Semi-Structured Methods, London: Sage.

Wischusen SM, Wischusen WE (2007). Biology Intensive Orientation for Students (BIOS) a biology "boot camp." CBE Life Sci Educ 6, 172-178.

Wischusen SM, Wischusen EW, Pomarico SM (2010). Impact of a short pre-freshman program on retention. J Coll Stud Ret 12, 429-441.

Wright R (2014). Why Meiosis Matters: The Case of the Fatherless Snake, CourseSource. www.coursesource.org/courses/why-meiosis-matters -the-case-of-the-fatherless-snake-0\#tabs-0-content=1 (accessed 19 March 2015). 